ANDREJA ŽELE

University of Ljubljana

Faculty of Philosophy

\title{
Частицы в словенском языке
}

К л ю ч е в ы е с л о в а: частица, служебные (коммуникативные) части речи, функциональные слова, модальная и соединительная роль частиц, текстовая модификация, сложные частицы-сращения

\section{0. О частицах - с точки зрения словенского языкознания ${ }^{1}$}

Частица - это самостоятельная функционально-синтаксическая часть речи, или функционально-синтаксический модификатор ${ }^{2}$, не имеющий ни предметного, ни грамматического самостоятельного значения, и как функционально десемантизированная или контекстуально ограниченная, а также формально неопределенная часть речи - так как она конкретизируется конкретным контекстуальным синтаксисом - не является членом предложения, типа seveda, точнее является пропози-

1 Для синтеза сделанных до настоящего времени заключений о словенских частицах я учитывала и комментировала исследования современных словенских лингвистов, таких как Й. Топоришича (Тoporišič 1991, 2000), И. Чернелич Козлевчар (Černelič Kozlevčar 1992), А. Видович Мухи (Vidovič Muha 1984, 2000), А. Скубиц (Skubic 1999), а также статьи из современных англо-американских, русских, чешских и словацких грамматик (цитируются в тексте статьи, библиографические данные приведены в списке литературы в конце статьи).

2 Модификатор в данном исследовании обозначает слово, вызывающее изменения в существующих семантических реляциях или привносит новые семантические реляции. 
ционным модификатором. При наименовании текстовых сопутствующих обстоятельств частица может быть в предложении т. н. контекстным (пропозиционным) наречием ${ }^{3}$, чаще неполным непредикативным предложением; частицы можно также определить как соотносительно-семантическое изречение. Частицы вводят новые семантические отношения и в то же время изменяют семантические отношения, и таким образом вносят в текст речевую динамику. Создают действенную/ динамическую реляцию, выражающуюся обычно закрытым глаголом; динамичность и пропозиционная значимость (выразительность) подтверждается также квалификатором «наречное употребление глагольной формы» (Jesenovec 1944: 529). Частицы являются текстовой частью речи, или только функциональными словами, поэтому словарные описания частиц (только) функциональный, лексикографически частицу можно определить как лексикализованную (словарную) референцию на речевой акт, поскольку частица - это сжатое воплощенное в слове речевое событие (т.н. резюме текста/предложения), сигнализирующее об изменениях обстоятельства текста, так как при помощи частиц говорящий устанавливает связь с потенциальным адресатом речи. Частицы как наименования или лексикализация скрытых речевых актов (в противовес, напр., полновыраженным фразеологическим единицам, Vidovič Muha 2000: 86-91) можно считать своего рода вспомогательными словами, при помощи которых говорящий устанавливает связь с контекстом и при этом выражает различные семантические и эмоциональные оттенки отдельных выражение или высказываний в контекстных или актуализационных отношениях. Поскольку частицы играют преимущественно текстовую роль, они являются смысловыми словами ${ }^{4}$, которые мы обычно умеем правильно использовать в тексте главным образом в своем родном языке; они сохраняют свою выраженно коммуникационную (коннекторную) роль, а вместе с этим выраженно вводное значение.

3 О частицах как о пропозиционных наречиях («rečenični prilozi») с точки зрения прагматического анализа модальности говорит еще Милка Ивич (Ivić 1973).

4 Неслучайно поэтому в традиционных словенских грамматиках в прошлом (напр., в грамматиках 1947, 1956 годов) частицы относятся к «мыслительным наречиям» («miselne prislove»). 
С коммуникативно-прагматической точки зрения частицы подразделяются на две основные группы: связующие (текстовые) частицы, исходящие из прагматических обстоятельств, и модальные (межличностные) частицы, исходящие из коммуникативных соотношений 5 . Связующие частицы подчеркивают когерентность и связанность текста, по этой причине они делятся на следующие подгруппы: дополнения (Pd), выбора (Pizbir), исключения (Pizvze), соединения или продолжения (Pnavez), замещения (Pnadom), противительные (Pnaspr), пояснительные (Ppojas), иллюстрирующие (Pponaz), выделительные/подчеркивающие (Ppoudar), резюмирования (Ppovze), оговорки (Pzadrž), удаления от темы (Pzastr); модальные частицы, относящиеся к участникам, обстоятельствам, глагольным процессам или к количеству, включают четыре подгруппы: эмоциональные (Nč), позывные (Np), оценочные (Nv) и отрицательные $(\mathrm{Nn})$. Как модальные, так и соединительные частицы не являются частью пропозиции, они ее только модифицируют, поэтому могут считаться модификаторами.

Дополнительно подчеркивает функциональности утверждение ${ }^{6}$, что частицы является следствием семантического опустошения слов, и таким образом они сохраняют только роль семантического нюансирования следующих за ними определяемыми слов, т. е. выражают только сопровождающие обстоятельства содержания, лексикализируемого определяемыми словами. В связи с этим и частицы соединительно-наречного (переходного) типа по причине того, что союзы не являются членами предложения, также выражают модальность высказывания в целом и манеру изложения (Vinogradov 1947: 733-737). Семантикосинтаксическую открытость частиц отражают и английские термины subordinating conjuction / subordinator? ${ }^{7}$ Согласно грамматике Квирка (Quirk), они относятся к подклассу наречий (subclass of adverbials) или предикационными частицами (predication subjuncts), выражающими

5 Эта классификация приводится по грамматики Холлидея (Halliday 1996), в Словении на примерах словенских частиц ее представил А.Э. Скубиц (Skubic 1999).

${ }^{6}$ См. (Виноградов 1947: 729).

7 На соотносительную роль частиц указывает также М. А. К. Халлидей (Halliday 1996: 81-84): Conjuctive Adjuncts вместе с Comment Adjuncts он включает в подгруппу 'модальныхчастиц' (Modal Adjuncts). 
субъектную ориентацию (subject-orientation) различными видами модальности. Это 'узкое личное понимание', связанное с высказыванием, а наряду с говорящим еще и с предикативным отношением, чаще всего включает в себя вежливость, подчеркивание и выделение 9 . К первоначальному функционально- и классификационно-структурному аспекту присоединяется в качестве вторичного еще и семантический аспект, который к определенным функциям добавляет различные комбинации семантических компонентов; их функциональная сфера может объединять семантические компоненты 'выделения', 'очевидности', 'исключения', 'дополнени” и 'оценочности, суждения': Gre predvsem za ironijo do samega sebe (Речь идет прежде всего о иронии по отночению к самому себе); Slačil se je, povsem se je razgalil (Он разделся; совершенно обнажслся); Ona je pravzaprav deklica (Она на самом деле девочка).

Частицы обычно трактуются как механические индикаторы выделения (Toporišič 1982: 295, 318). В рамках фонетики предложения они выражены падающей полукаденцией и таким образом интонационно связаны со следующим членом предложения, с которым составляют интонационное целое. Таким образом, они зачастую влияют также и на звучание предложения.

Актуальность, которой вообще-то не уделяется должного внимания, в «Словаре словенского литературного языка» (SSKJ) ${ }^{10}$, по крайней мере, частично покрывают обстоятельственные (прагматические) элементы, выраженные модификационными частями речи, такими как частица и междометие - обе части речи представляют собой словар-

${ }^{8}$ По Квирку (Quirk ${ }^{20} 1994:$ 567-612), наиболее частотны предикационные частицы, напр., zares (действительно), за ними следуют временные (time-relationship subjuncts), напр., že (уже), še (еще), менее частотны 'выделители' (emphasizers), напр., seveda (конечно), zares (действительно), 'градации' (intesifiers) 'увеличения', напр., povsem (совершенно), 'уменьшения' (downtoners), напр., skorajda (почти совсем), и своего рода 'ограничители' (focusing subjuncts), напр., predvsem (nрежде всего).

9 Я учитывала английские лингвистические словари, такие как NTC's Dictionary of Grammar Terminology (1991) и A Dictionary of Linguistics and Phonetics $\left({ }^{4} 1997\right)$.

10 Необходимо учитывать оговорку составителей (А. Vidovič Muha 1993: 38) о том, что словарь не воспроизводит причинно-следственной связи между членами предложения и частями речи - в нем еще не реализуется функциональноструктуралистский аспект, когда базовая текстовая структура, напр., основная модель предложения, определяет части речи. 
ное воплощение речевого акта, значение которых определяет создатель текста или момент речи или момент создания текста. Требование постоянной актуализации текстового материала закономерно и обосновано, ведь только в тексте реализуется действительная информативность анализируемых лексем. С точки зрения прагматической ситуативности и функциональности граница между актуализацией высказывания или текста и эмоциональной окраской высказывания или текста является одновременно и ориентационным разграничителем между частицами и междометиями; и если частицы имеют коммуникативное (актуализационное) значение, то междометия имеют обычно в первую очередь эмоциональную и лишь минимальную нецелевую коммуникативную значимость.

\section{1. Частиречные свойства частиц}

- Частица - это часть речи, не являющаяся членом предложения, но при этом являющая модификацией или модификатором члена предложения, предложения или текста (Vidovič Muha 1984: 144). Структурно-синтаксическим отличием от междометий заключается в том, что частицы ${ }^{11}$ обычно включены в предложение (Černelič 1991: 83). Семантико-синтаксически частицы обычно представляют собой модификационный компонент предложения, а с коммуникативной точки зрения являются компонентами речевого акта, актуализирующими лексикализированный акт или содержание. Учитывая вышесказанное частицы - типично паразитическая часть речи.

- Типичная неизменяемость в случаях частиц-сращений (слияний) является следствием того, что в их основе речевые основы - предложения или словосочетания, уже имеющие определенную внутреннюю структурно-морфологическую организацию. Существующие колебания с одним или несколькими ударениями развиваются в направ-

11 Особо проанализированы частицы - неполные непредикативные предложения. Семантически важной является информация о том, что в традиционной грамматике словенского языка они трактуются как мыслительные наречия, см. «Словенскую грамматику» (Ss 1956, 261-264). Вслед за академической грамматикой словацкого языка, типология таких частиц имплицитно приводится в «Словенской грамматике» 1976 года (384-385). 
лении унификации, слияния в одно слово с одним ударением, свойственным для фразеологических сочетаний.

- Частицы устанавливают связь с контекстом ${ }^{12}$, это предложения в предложении. В них могут формироваться даже синтаксические наклонения. Эта модальность в рамках модификационности придает семантической основе высказывания окончательный облик, а потому активно включена в процесс вербализации, но при этом она контекстуально окказиональна ${ }^{13}$. Так, например, т. н. мыслительные частицы указывают на косвенную речь, напр., France je baje bolan (Вроде бы, Франи болен), Zamahnil je z roko, češ da se ne splača (Oн махнул рукой, мол, не стоит) (Toporišič 1976: 531).

Зачастую наблюдаются конверсионные отношения между частицами и союзами, преимущественно сложение (фразеологизация) становится причиной частиречного пересечения частиц и союзов, напр., сееtudi (если бы и, хотя бы и ), сеерrav (хотя) (Tороrišič 1976: 363, 367).

\section{2. Словообразовательные свойства частиц (сложение) $)^{14}$}

Установлено, и узус это подтвержддает ${ }^{15}$, что исконный и типичный способ образование частиц - это главным образом сращение (слияние) $^{16}$. Ядром частиц-сращений (слияний), в словацкой академической грамматике называемых 'вторичными частицами' (sekundárne

12 И шире с целостным контекстом, который включает также и нетекстовые обстоятельства коммуникации (см. Торorišič 1993: 8).

13 Использование частиц охватывает аж девять видов или модификаций вербализации от тринадцати рассматриваемы в «Новой грамматике словенского языка» (NSS (Toporišič 1982: 225-295): подлинность, возможность, отрицание, иерархия, синтаксическая модальность, уверенность, градация, эмоциональность, актуальность; кроме: качества, желательности, участия и моментности.

14 Исторически заключения Миклошича (Miklošič 1875: 350) о семантико-синтаксической независимости компонентов сращения и их семантико-формальном совпадении со словосочетание, от которого образуется сращение, дополняются критерием Брезника о сохранении исходных ударений на компонентах производной основы (Breznik 1944: 316-319).

15 Последний раз в учебнике Й. Топоришича для средней школы «Slovenski jezik in sporočanje 2» (J. Toporišič, Maribor: Obzorja, 1998, 136).

16 В словенском языкознании типичными словообразовательными признаками сращения (слияния) считаются: а) омонимичность окончаний и суффиксов и отсутствие соединительного форманта, б) численная нерелевантность и семантиче- 
častice, 753), обычно является глагол, который может усекаться или опускаться: seveda (конечно), тоrebiti (может быть); morda (быть может, возможно), baje (говорят, вроде бы); resda (действительно), gotovoda (наверняка), kajpa (как же иначе), kajpada (разумеется), kajpak (разумеется, правда), bržkone (наверняка), najbrž (вероятно), kajnе (не так ли), najsibo (будь то ... или); подчеркнуто выступает реляция выделения в таких примерах, как skoraj (почти, чуть ли не) - skorajda (чуть ли не), kajpa - kajpada (разумеется,наверняка), kakopa - kakopada (конечно, как же иначе) и т. п.

Частицы по способу образования - часто встречается конверсия частично подобны наречиям: конверсия из предикатива, напр., zagotovo (наверняка), конверсия из наречия, напр., navsezadnje (в конце конщов), конверсия из союза, напр., с̌etudi (xотя, пусть и). Некоторые частицы можно было бы считать «стершимися сращениями» (Toporišič 1998: 124), о чем на формальном уровне свидетельствует наличие одного ударения.

Наиболее частотные сращения (на материале для SSKJ и в сопоставлении с материалом корпуса текстов)

Сращение - это типичный способ вербализации речевого акта. Частицы-сращения, также как и междометия, исходной основой и трансформационными возможностями связаны с пропозицией. Эта связанность, с одной стороны, в семантико-синтаксическом плане освобождает частицы, а с другой, делает сращение наиболее распространенным способом образования частиц ${ }^{17}$.

В Словаре словенского литературного языка все нижеприведенные сращения помечены как наречия (prisl(ov)), обычная для частиц модальность маркирована пометой экспрессивное (ekspr(esivno)). Для словенских частиц-сращений помимо словарного толкования приведена также частотность употребления, т. е. количество появлений в корпусе

ская и формальная независимость исходных слов, в) преобразовательное равенство всех слов (Vidovič Muha 1988: 32).

17 Частицы чаще всего образуются от глаголов или предикативных выражений, чаще всего усечением. На материале словенского языка об этом см. Jesenovec (1944) и Toporišič (1982: 272). 
текстов Gigafida (выборка на 18. 9. 2012 г.), частицы приведены в порядке уменьшения употребительности:

- predvsèm (прежде всего) 'ограничение самым важным' : povsèm (совсем) 'совершенно' (785.000);

- sevéda (конечно) 'очевидность', 'согласие' (752.000);

- pràvzapràv (на самом деле) 'выяснение, знакомство с ситуацией', 'поправка' (200.000);

- zagotóvo (наверняка) 'категоричность чего-л.' (168.000);

- nàjbrž /nájbrž (вероятно) ‘большая вероятность’ (121.000);

- zarés (действительно) 'подкрепление' (107.000);

- nazádnje (наконец) 'логически ожидаемый результат действия/ события' (97.000);

- skôrajda (почти) ekspr. 'значительное приближение полной меры/ степени' (54.100);

- navsezádnje (в конце концов) 'ограничение' (43.000);

- résda (правда) 'подкрепление утверждения' (30.000);

- bŕžkone (весьма вероятно) ‘большая вероятность' (25.000);

- kájpak/kájpa/kájpada (наверняка, а как же иначе) 'очевидность утверждения' (19.000/68/6.500);

- potemtákem (таким образом, следовательно) ‘причинно-следственное заключение' (15.000);

- kajnè (не так ли) 'ожидание согласия' (14.500);

- kàrsedá (насколько возможно) 'наивысшая возможная мера' (4250);

- kajnèda (не так ли) 'ожидание согласия' (600);

- bŕžda ([весьма] вероятно) ‘большая вероятность’ (350);

- kajnèdane (разве не так, не так ли) 'ожидание согласия' (--);

Разумеется, красноречивее самих цифр говорит численное соотношение между отдельными частицами. Наивысшая употребительность для типично текстовой части речи ожидаема.

\section{3. Семантико-синтаксические или функциональные текстовые свойства частиц}

- Частицы обычно чаще всего выступают как модификационные неполные непредикативные предложения, составляющие и выражающие т. н. модальный пласт высказывания или даже синтаксического 
целого более высокого уровня. Как предложения, состоящие из частиц, так и междометные предложения не имеют собственного информационного значения.

- Частотность сращений в роли частиц подтверждает тот факт, что частицы не являются членами предложений, и в то же время свидетельствует о текстовых характер частиц-сращений.

- Частицы не создают конкретных пространственных/временных отношений - это функция наречий, являющихся членами предложения, - они обычно выражают относительные или понятийные окказиональные семантико-синтаксические отношения и уже обозначенную объектность лишь модифицируют с учетом переживаний говорящего. Основная и преобладающая релятивистская семантико-синтаксическая роль подчеркивается и в других языках, напр., в английском «the clause-relating functions» (Carter 1998: 83) и в русском «общее значение отношения» (Русская грамматика I, 1980). Частицы-сращения широко используются, прежде всего, в 'речевом дискурсе' (Carter 1998: 93), т. е. в речи, поскольку помимо семантико-синтаксического аспекта позволяют исчерпывающе учитывать также и прагматический аспект. Модальность и постоянная сопроводительное семантико-синтаксическое свойство частиц-сращений, т. е. т. н. составных частиц включает: а) эмоциональную и другую оценку как непосредственную реакцию говорящего, б) приказы/требования, в) различные отношения/реляции сообщения между источником/творцом и другими участниками и различными событиями и фактами коммуникации. Одним словом, обобщенное семантикосинтаксическое отношение дает широкие возможности использования семантики в зависимости от конкретных синтаксических требований или условий конкретного текста.

Подчеркнуто соотносительная и соединительная роль частиц устанавливает семантико-синтаксические соотношения с контекстом, а в речи также ситуационные соотношения с обстоятельствами коммуникации, таким образом регулярно происходят семантико-синтаксические искажения между модальной и соединительной функциями, что функционально сближает частицы с союзами. Приведем несколько случаем преимущественно союзного использования частиц из приведенных выше примеров: Potem bi se vrnila (Тогда я вернусь/я бы [пожа- 
луй] вернулась). Seveda sama, Boji se zveri (Конечно одна, Она боится диких зверей). Kajpada теdvedov tиdi (Разумеется, медведей тоже).

\section{1. Модальная роль частиц}

Семантико-синтаксическая обособленность в форме возможного пропозиционного значения и синтаксической многозначности позволяет частицам выделять наиболее частотные синтаксические значения посредством определения смысла высказывания или предложения. Таким образом выявляются речевые позиции и ситуации, в которых словенцы чаще всего используют частицы.

Модальные частицы, как и ожидалось, наиболее частотны, так как выражение модальности в процессе вербализации является их основной функцией: Kdor ne najde nobene povezave, se seveda moti (Tom, кто не находит никакой связи, конечно, ошибается) (с преобладанием PS 'эмоциональности'), Stari Marinč je bil kajpa slep in gluh (Cmaрый Маринч был, разумеется, слепым и глухим ) (.../, Vrata bodo seveda odklenjena (Дверь будет, конечно, открыта) (с преобладанием PS 'cогласия'), Bržkone so to pobožne želje nekaterih ljudi (Вероятно, это благие желания некоторых людей) (с преобладанием PS 'вероятности’), Tо je pravzaprav njena edina sreča (Это в действительности наша единственная надежда) (с преобладанием PS 'предположения'), Našli so pravzaprav samo še eno truplo (На самом деле, нашли только ещче один труn) (с преобладанием PS 'оговорки').

На первый план выходят оповещательная, призывной и контактная роль в тексте, которые являются в некотором роде эмоциональной/модальной надстройкой само собой разумеющейся отражательной роли реальности и явлений ${ }^{18}$. (Приведены в порядке снижения употребительности): a1) ‘подкрепление утверждения’ (Tako dobro se ti seveda ne bo več godilo; Ne bom več toliko delal, primojsvet da ne); a2) 'подкрепление-отрицание' (To je storil vragvedikdo, Vragvedi, če je še kaj varno); b) 'отрицание' (Bogvaruj povedati komu; Vseeno, morali bi si vzeti čas); c) 'предупреждение' (Bogvaruj da bi se mu približal); č) 'призыв’ (Ali bo kaj?!); d) 'ограничение' (Zamisel je resda dobra, samo izvedljiva ni); $\mathrm{d}_{1}$ ) 'ограничение по

18 Наименования ролей в тексте приводятся по «Slovenski jezik in sporočanje 1» (Maribor: Obzorja, 1997, 199-200). 
важности' (Bil je predvsem miren); $\mathrm{d}_{2}$ ) 'ограничение по абсолютности' (Bil je povsem miren); е) различные эмоциональные состояния: е e $_{1}$ 'želja' (To bo zdaj le v redu); е ${ }_{2}$ ) 'уверенность' (Zagotovo bo boljše!).

\section{2. Соединительная роль частиц - коннекторные частицы}

Частицы это такие слова, которые, не являются членами предложения, которые в тексте играют роль коннекторов, связывающих между собой высказывания, предложения текста. Коннекторы прежде всего устанавливают реляции, поэтому к коннекторам, изначально не являющимися членами предложения, можно отнести и частицы. Таким образом, коннекторы - это, прежде всего, текстовые соединители, являющиеся при этом и модификаторами пропозиционных отношений в тексте, т. е. основные реляционные модификаторы в тексте, преимущественно соединительные частицы вводят своего рода вспомогательные высказывания и устанавливают соотношение с контекстом, поэтому они в первую очередь текстовое явление. Частицы в коннекторной роли - это своего рода дополнительное сообщение. Частицы обязательно семантически/информационно модифицируют, т. е. изменяют текст, и в этим они отличаются от союзов. К типичным частицам-коннекторам относятся: с̌ег̌ (мол) ${ }_{2308}$, le (только) ${ }_{2.270 .000}$, samo (только) ${ }_{770.000}$ (c фразеологическими вариантами с̌eš $d a$ (мол), samo da (только лишь) и коннекторные частицы-сращения с̌еprav (xотя) ${ }_{612.000}$, četudi (xотя) ${ }_{52.500}$, predvsem (преимущественно), resda (действительно), seveda (конечно), vsekakor (непременно) ${ }_{160.000}$ ); а также частично-наречные комбинации, напр., prav tako (точно также, а также) 280.000 , и частично-союзные, напр., in tudi nе (и также не) $)^{19}$.

Частицы в коннекторной роли в высказывание с обычным интонационным и актуальным членение (с повествовательной каденцией и членением на тему и рему, т. e. topic-comment расположением) могут вносить изменения, так что в рамках одного высказывания начальной актуализацией темы создается интонационная каденция и таким образом два интонационных верха, являющихся коммуникационными ядрами, напр., Ni bilo praktično nobenih mimoidočih ... Samo drobna starka je pred seboj potiskala napol prazen voziček (Не было практически

19 Для найденных частиц приводится частота употребления в корпусе Gigafida. 
никаких прохожих... Только маленькая старуха толкала перед собой полупустую тележку) (Běličová, Uhlířová 1996: 199).

Учитывая вышесказанное, коннектор - равноправный носитель интонационного центра высказывания, напр., Tja ne grem, tako ali tako ${ }_{31.000}$ nimam možnosti zmagati (Я туда не пойду, все равно у меня нет шансов выиграть) (Daneš 1999: 152, Daneš 2000: 168-169).

\section{4. О частицах в лексикологическом и лексикографическом аспекте}

Ниже семантико-синтаксические роли будут представлены также с лексикографической точки зрения с учетом материала словаря (SSKJ) и актуального корпуса текстов. Помимо этого учитывается также лексикографическая обработка частиц частиц Г. Хельбига (Helbig²1990).

Для примера представим сопоставительное лексикографическое описание несколько типичных частиц иллюстративно с учетом наиболее выделенных семантико-синтаксических ролей в рамках основных модальных $(\mathrm{N})$ и соединительных групп (Р). Принцип описания частиц в словарной статье следующий: 1) соединительная (Р) или модальная $(\mathrm{N})$ роль частиц, 2) функциональное пояснение с приведением типичных глаголов: izraža (выражает), krері (подкрепляет), отејије (ограничивает), ороzаrја (указывает), роиdаrja (подчеркивает), stopnjuје (усиливает), utemeljuje (обосновьвает), иvaja (вводит), 3) место или положение в тексте - относится ли частица к слову, части высказывания или к предложению в целом, 4) примеры предложений и 5) возможные синонимы. Лексикографическое или лексикологическое представление как раз благодаря учету всех вышеперечисленных критериев помогает наиболее целостно и семантико-соотносительно охарактеризовать частицы.

Приводится словарное описание частиц, напр., morda (может быть), $\mathrm{Nv}=$ оценочная модальная частица:

mordà tudi mórda (à; ộ) Nv 1. izraža verjetnost, ne popolno prepričanost $o$ čem: rad bi vedel, če me morda še pozna; zvečer se morda vidiva; morda se vendar vrneš domov / draži jo ne morda iz hudobije, ampak iz prešernosti; morda bo kaj iz tega, morda nič |Obstaja možnost, Možno je|, sin. morda, morebiti 2. izraža približno najvišjo mero povedanega: dosti ni popil, tri kozarce morda 
|Zdi se / Kaže, da ...|, sin. kvečjemu 3. v zvezi z bi izraža obzirno željo, zapoved: morda bi se pomaknili nekoliko naprej; morda bi še enkrat začeli |Ali je možno, Bi bilo možno| 4. izraža vljudnostno in obzirno vprašanje, prošnjo: bi morda še kaj popili; ali bi morda kaj prispevali; ali morda še kaj želite |Smemo upati, da bi ...| 5. izraža zadržano pritrjevanje: mislim, da bo tokrat šlo. Morda |Upajmo?!| 6. $v$ retoričnem vprašanju poudarja nasprotno trditev: kdo me bo strahoval, morda ti, ki te nič ni |Kaj si domišljaš|, sin. mar

\section{5. В качестве заключения}

Одним словом, для ясной и эффективной коммуникации необходимо овладеть как можно большим количеством лингво-прагматических возможностей и в рамках нормативно-стилистических требований учитывать их при создании текстов. Отношение к сказанному и обстоятельствам речевой ситуации в целом выражают частицы, поэтому функционально это крайне живые компоненты языка повседневного общения, которые благодаря своей семантико-реляционной роли актуализируют выраженное словами и одновременно могут повышать информативность и выразительность высказывания.

\section{Источники и литература}

BĚličová H., Uhlířová L., 1996, Slovanská věta. Slavistické monografie. Řada lingvistická sv. 3, Praha: Euroslavica.

BREZNIK A., 1944, Zloženke v slovenščini, Ljubljana, AZU.

CARTer R., ${ }^{2} 1998$, Vocabulary Applied Linguistic Perspectives, London-New York: Routledge.

Cobuild Learner's Dictionary, 1999, London: HarperCollins Publishers.

Crystal D., ${ }^{4}$ 1997, A Dictionary of Linguistics and Phonetics, Oxford: Blackwell Publishers,.

ČERnELIČ I., 1991, Členek kot besedna vrsta v slovenskem knjižnem jeziku, Jezikoslovni zapiski 1, Ljubljana: ISJ, ZRC SAZU, s. 73-85.

ČERNELIČ-KozLeVČAr I., 1992, O delitvi členkov, Vprašanja slovarja in zdomske književnosti, Ljubljana: Slavistično društvo Slovenije, s. 213-227.

DANEš F., 1999, Př́spěvek k rozboru významové výstavby výpovědi, v: O. Uličný (ur.), Jazyk a text I. Výbor z lingvistického díla Františka Daneše. Část 1, Praha: Univerzita Karlova v Praze, Filozofická fakulta, s. 67-78. 
DANEŠ F., 1999, Intonace v textu promluvě, v: O. Uličný (ur.), Jazyk a text I. Výbor z lingvistického díla Františka Daneše. Část 1, Praha: Univerzita Karlova v Praze, Filozofická fakulta, s. 142-163.

DANEš F., 1999, O koherenci textu hovorů, v: O. Uličný (ur.), Jazyk a text I. Výbor z lingvistického díla Františka Daneše. Č́st 2, Praha: Univerzita Karlova v Praze, Filozofická fakulta, s. 424-437.

DANEŠ F., 2000, Order of elements and sentence intonation, v: O. Uličný (ur.), Jazyk a text II. Výbor z lingvistického díla Františka Daneše, Praha: Univerzita Karlova v Praze, Filozofická fakulta, s. 160-175.

Fidaplus, http://www.fidaplus.net/

Gigafida, http://www.gigafida.net/

Halliday M. A. K., 1996, An Introduction to Functional Grammar, New York: St. Martin's Press Inc.

Helbig G., ${ }^{2} 1990$, Lexikon deutscher Partikeln, Leipzig: Verlag Enzyklopädie.

Ivić M., 1973, Problematika modalnih rečenica, v: Otázky slovanské syntaxe III, Brno: J. E. Pukryne, s. 85-91.

JAKOP N., 2000/01, Funkcijska delitev členkov: značilnosti naklonskih členkov, Jezik in slovstvo 46/7-8, s. 305-316.

Jesenovec F., 1944, Pomenske funkcije slovenskih členic, v: N. Velikonja, B. Borko, T. Debeljak, Z. Simčič (ur.), Zbornik zimske pomoči, Ljubljana, s. 529-536.

Miklošı̌ F., 1875, Vergleichende Stammbildungslehre der slavischen Sprachen, Wien.

QUIRK R. idr., ${ }^{20} 1994$, A Comprehensive Grammar of the English Language, New York: Longman.

Rusínová Z. (ed.), 1986, Mluvnice češtiny 2. Tvarosloví, Praha: Academia.

RužIČKA J. (ed.), 1966, Morfológia slovenského jazyka, Bratislava: Slovenská akadémie vied.

SimeOn R., 1969, Enciklopedijski rječnik lingvističkih naziva, Zagreb: Matica hrvatska.

SkUBIC A., 1999, Ogled kohezijske vloge slovenskega členka, Slavistična revija 47/2, s. 211-238.

Slovar slovenskega knjižnega jezika, 1970, 1975, 1979, 1985, 1991. Ljubljana: DZS.

SPEARS A. R., 1991, NTC's Dictionary of Grammar Terminology, Lincolnwood: National Textbook Company (NTC).

TOPORIŠıč J., 1976¹, 20004 , Slovenska slovnica. Založba Obzorja Maribor.

TOPORIŠIČ J., 1982, Nova slovenska skladnja (NSS). Ljubljana: DZS.

TOPORIŠIČ J., 1991, Členki in njihovi stavčnočlenski ustrezniki, XXVII. Seminar SJLK, Ljubljana: FF, s. 3-16.

TOPORIŠıč J., 1997/8, Slovenski jezik in sporočanje 1, 2, Maribor: Založba Obzorja.

Vidovič Muna A., 1984, Nova slovenska skladnja J. Toporišiča, SR 32/2, s. 142-155. 
Vidovič Muna A., 1988, Slovensko skladenjsko besedotvorje ob primerih zloženk, Ljubljana: Znanstveni inštitut Filozofske fakultete, Partizanska knjiga.

Vidovič Muna A., 2000, Slovensko leksikalno pomenoslovje. Govorica slovarja, Ljubljana: Znanstveni inštitut.

Виноградов В. В., 1947, Грамматическое учение о слове, Москва: Русский язык.

\section{Particles in Slovenian}

( su m mary)

In order to have clear and effective communication one needs to keep open as many linguistic and pragmatic options as possible and utilise them in the formation of texts in the context of normative-stylistic requirements. The relation to what is being said and the circumstances of the spoken situation are expressed particularly through particles, which is why they are functionally very lively linguistic components of everyday communication. With their semantic-contextual role they actualise what is expressed and at the same time condense the message. The particle is one of those non-parts-of-speech that fulfils the textual role of the connector and is, more particularly, ranked among inter-predicate connectors or the connectors in suprapredicate texts. In particular, connectors establish relations, which is why particles may also be counted among the original non-part-of-speech connectors. Connectors are therefore textual cohesive devices and modifiers of propositional relations in the text; particle connective items in particular introduce a sort of co-predicate and the relation to the context, which is why they are mostly textual phenomena.

Since particles play primarily a textual role, they are also particularly meaningful words, which can be reasonably used in a text, especially in one's first language; they maintain a strong communicative (connective) role. From the communicativepragmatic perspective, particles are divided into two main categories, namely the connecting (text) particles resulting from pragmatic circumstances, and mood (interpersonal) particles resulting from communicative relationships. Mood particles focus either on the participants, the circumstances, the verbal process or the quantity, e.g. bogvaruj, končno, dejansko, baje, nikar, while the connecting particles highlight textual coherence and cohesion, e.g. celo, kaj šele, drugače, sicer pa, torej, etc. The most comprehensive and functional semantic-circumstantial evaluation of particles can be found in lexical representation. 
